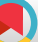

\title{
Review of Rationale, Design, and Initial Findings: Tehran Lipid and Glucose Study
}

\author{
Fereidoun Azizi ${ }^{1, *}$, Azita Zadeh-Vakili ${ }^{2}$ and Miralireza Takyar ${ }^{1}$ \\ ${ }^{1}$ Endocrine Research Center, Research Institute for Endocrine Sciences, Shahid Beheshti University of Medical Sciences, Tehran, Iran \\ ${ }^{2}$ Cellular and Molecular Endocrine Research Center, Research Institute for Endocrine Sciences, Shahid Beheshti University of Medical Sciences, Tehran, Iran \\ "Corresponding author: Endocrine Research Center, Research Institute for Endocrine Sciences, Shahid Beheshti University of Medical Sciences, Tehran, Iran. Email: \\ azizi@endocrine.ac.ir
}

Received 2018 September 01; Revised 2018 October 02; Accepted 2018 October 06

\begin{abstract}
In the late 1990s the non-communicable diseases were becoming increasingly more prevalent and a significant proportion of evidence in this regard had originated from industrialized "Western" countries. This had led to a landscape where most national and local health decisions regarding non-communicable diseases (NCDs) were informed by data generated elsewhere. Iran, as a large country in the Middle East was no exception and was going through significant population growth and urban development at the time. An initiative by the Iranian National Scientific Research Council funded an idea that was aimed at delineating the local epidemiology of NCDs and their risk factors in a manner that was unprecedented. The result was Tehran Lipid and Glucose Study (TLGS), the first and longest running cohort of its sort in Iran. Initial data out of TLGS reported the characteristics of 15005 people aged over 3 years in a representative population of Tehranians. Additionally, distribution and prevalence of cardiovascular risk factors among the study population were characterized. This population was selected through a multistage stratified cluster random sampling technique from the population of district 13 in Tehran. In addition, TLGS gave rise to a great deal of important and highly effective initial findings on national cut-off points for various variables, information about nutrition, hypertension, dyslipoproteinemia, and metabolic syndrome. TLGS also generated information about metabolic health indicators among children and adolescents. Here we present a brief overview of rationale, design, and initial findings of TLGS.
\end{abstract}

Keywords: Non-Communicable Diseases, Tehran Lipid and Glucose Study, Iran

\section{Context}

In the late 1990s, the spiraling epidemic of noncommunicable diseases was a disturbingly palpable presence and a relatively widely accepted reality of life all over the world (World Health Report, 1998). However, the level of knowledge and evidence on these challenges varied greatly and a significant proportion of evidence in this regard had originated from industrialized "Western" countries. Therefore, decisions at national and local levels in other countries were mostly based on the evidence generated elsewhere.

Iran is a country in the Middle East region comprising a land area of $1648195 \mathrm{~km}^{2}$ that has continuously been undergoing significant population growth and changes in its urban development over the past four decades. As one of the most advanced countries in the region in terms of science and practice of medicine and health systems, Iran has taken solid steps towards developing a sound basis for im- provement of health care. For example, assessment of the epidemiological status of, and successful implementation of interventions to control, iodine deficiency disorder (1) and implementation of a national program for newborn hypothyroididsm screening (2) are two of the successful public health campaigns that have taken place over the past decades. Therefore, this country is well equipped to expand the regional knowledge of health and diseases.

Similar to other countries that have experienced rapid and significant economic and demographic alterations, Iran has experienced a period of nutrition transition (3) and the prevalence of non-communicable diseases (NCDs) has increased, making them the main health challenge and significant causes of mortality and morbidity in Iran (4-7). This trend started in the 1980s and necessitated a more active approach to epidemiological study of NCDs in Iran in a manner that could inform national policies. 


\section{Rationale for Design of Tehran Lipid and Glucose Study}

As mentioned above, the prevalence of NCDs has been on the rise. Over the years, progress has been made in the treatment of NCD and in the pharmacological control of many risk factors. However, the most cost-effective and sustainable way of controlling these diseases is through reducing the prevalence of risk factors in a population. This can be done through lifestyle changes such as increasing regular physical activity, eating healthily and remaining tobacco-free (8-10). Along these lines, the Iranian National Scientific Research Council launched an initiative from 1995 to 1997 through which it would fund selected national research projects. The idea of Tehran Lipid and Glucose Study (TLGS) was first conceived and put forward to the Council within the above-mentioned framework in 1997. It was among the very few national projects that were funded.

Tehran city covers an area of $1500 \mathrm{~km}^{2}$ and consists of 22 districts with a total population of over ten million people. The TLGS is a large scale community based prospective study performed on a representative sample of residents of district-13 of Tehran, capital of Iran. The TLGS was first designed in 1997 and implemented in 1999 with the aim of studying epidemiology of NCD risk factors and outcomes of NCDs in a manner that was previously unprecedented in Iran (4).

The first phase of TLGS was a cross-sectional study on residents of district 13 in Tehran (between 3 to 69 years of age) that assessed the prevalence of cardiovascular diseases and their risk factors (Figure 1). The second phase, however, started in 2002 and was designed as a longitudinal study with an anticipated duration of at least 20 years, which has continued to date. Data collection in this phase was planned to be performed in 3-year intervals. A detailed explanation of the study population, baseline measurement and follow-up visits have been presented before (3). The year 2018, marks the start of the seventh 3-year data collection cycle.

\section{Initial Findings of Tehran Lipid and Glucose Study}

3.1. Initial Characteristics of the Study Population and Demographic Findings

Initial data out of TLGS reported the characteristics of 15005 people aged over 3 years in a representative population of Tehranians. Additionally, distribution and prevalence of cardiovascular risk factors among the study population were characterized. This population was selected

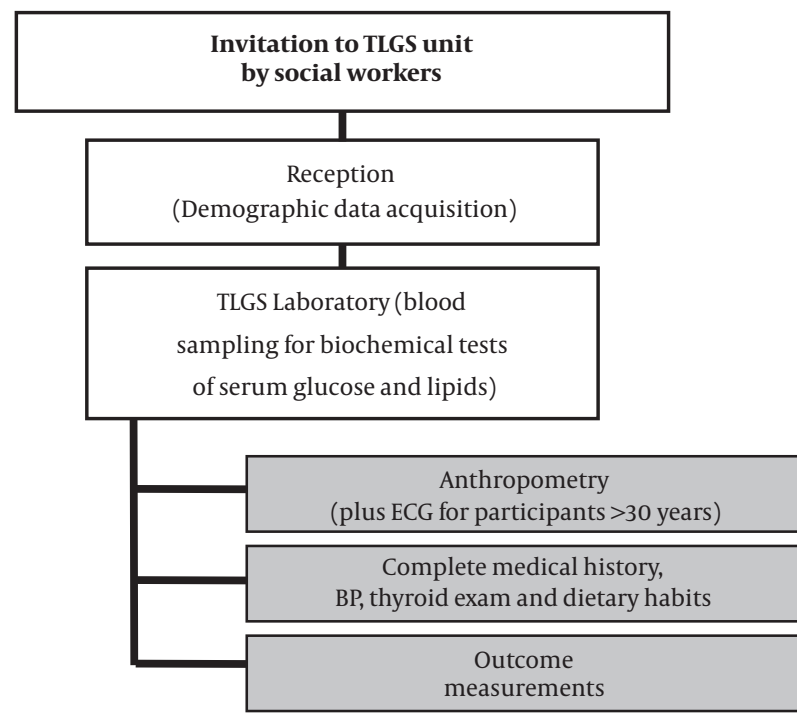

Figure 1. Study design of the phase I of the TLGS. Abbreviations: TLGS, Tehran Lipid and Glucose Study; ECG, Electrocardiogram; BP, Blood Pressure.

through a multistage stratified cluster random sampling technique from the population of district 13 in Tehran. At the time, Tehran was composed of 20 urban districts and made up a population of 6.7 million (Iran National Census 1996). District 13 was chosen mainly because city-wide data showed a high rate of stability in that district. Also, the age distribution in district 13 was representative of the overall population in Tehran.

The study population comprised 15005 Tehranian children, adolescents, and adults, 44\% males and 56\% females. Nearly, $5 \%$ of the study population was between 3 - 6 years, 6\% between 7 - 10 years, 9\% between 11 - 14 years, 19\% between 15 - 24 years, 17\% between 25 - 34 years, 16\% between 35 - 44 years, $12 \%$ between 45 - 54 years, and 10\% between 55 - 64 years, and 7\% over 64 years. Age and sex distributions are shown in Table 1.

Initial findings of TLGS shed some much anticipated light on the smoking habits of the Tehranian population older than 15 years of age. It was shown that $10.6 \%$ of the population were daily smokers, while $1.5 \%$ were occasional smokers, 6.1\% ex-smokers, and 81.8\% non-smokers.

Moreover, other key demographic information became available within the context of TLGS (some of the more important ones are summarized in Table 2 ).

\subsection{National Cutoff Points}

A major contribution of TLGS that became tangible in its early years was defining cutoff points that were spe- 
Table 1. Age Distribution of Tehran Lipid and Glucose Study (TLGS) Participants Based on the WHO STEPS Categories ${ }^{\mathrm{a}}$

\begin{tabular}{|c|c|c|c|}
\hline Age Groups (y) & Men & Women & Total \\
\hline $3-6$ & $336(49.1)$ & $349(50.9)$ & $685(4.6)$ \\
\hline $7-10$ & $469(49.2)$ & $484(50.8)$ & $953(6.4)$ \\
\hline $11-14$ & $667(49.9)$ & $670(50.1)$ & $1337(8.9)$ \\
\hline $15-24$ & $1195(42.0)$ & $1650(58.0)$ & $2845(19.0)$ \\
\hline $25-34$ & $985(39.8)$ & $1489(60.2)$ & $2474(16.5)$ \\
\hline $35-44$ & $1011(42.6)$ & $1360(57.4)$ & $2371(15.8)$ \\
\hline $45-54$ & $724(39.8)$ & $1094(60.2)$ & $1818(12.1)$ \\
\hline $55-64$ & $624(43.0)$ & $827(57.0)$ & $1451(9.7)$ \\
\hline$\geq 65$ & $599(55.9)$ & $472(44.1)$ & $1071(7.1)$ \\
\hline Total & $6610(44.1)$ & 8395 (55.9) & $15005(100.0)$ \\
\hline
\end{tabular}

${ }^{\mathrm{a}}$ Values are expressed as number (\%).

Table 2. Important Demographic Characteristics of Tehran Lipid and Glucose Study (TLGS) Participants at Baseline

\begin{tabular}{|cc|}
\hline & No. (\%) \\
\hline Marital status (age $\geq \mathbf{1 5})$ & $3071(25.5)$ \\
\hline Single & $8328(69.2)$ \\
\hline Married & $631(5.3)$ \\
\hline Divorced/widowed & \\
\hline Literate ${ }^{\text {a }}$ (age $\left.\geq 7\right)$ & $5997(95.6)$ \\
\hline Men & $7246(90.1)$ \\
\hline Women & \\
\hline At least one university degree (age $\geq \mathbf{2 0})$ & $746(18)$ \\
\hline Men & $515(10)$ \\
\hline Women & \\
\hline Employed (age $\geq \mathbf{1 0})$ & $3195(62)$ \\
\hline Men & $606(9)$ \\
\hline Women
\end{tabular}

${ }^{\mathrm{a}}$ Literate is defined as being able to read and write.

cific to an Iranian population for various variables. One of the early reports from TLGS reported cutoff points for anthropometric measures as indicators of cardiovascular risk factors in an Iranian population of 10522 (11). Results of this study suggested that many of these cutoff points were higher for the Iranian population compared with other Asian populations. Studies with such intentions continued in the TLGS and population-specific cutoff values for many other parameters were defined. Some of these values, for example that for TSH, are reviewed in various articles in this issue.

\subsection{Nutrition}

TLGS was designed and has been conducted and maintained with the importance of nutrition and nutritional interventions in mind. This perspective came to fruition not very long after the start of this cohort. Initial assessment of nutritional habits of the TLGS population resulted in a comparison between mean servings of intakes of various food groups among Tehranians and those set forth in the Food Guide Pyramid (Figure 2) (12). A cross-sectional study on 403 TLGS participants older than 25 years of age was designed and conducted to assess diet and energy expenditure and requirement of adults in Tehran. The findings revealed that an average Tehranian has an energy requirement that is lower than daily allowances recommended by $\mathrm{FAO} / \mathrm{WHO}$ and highlighted the need for interventions aimed at improvement of dietary habits in urban populations in Iran (13). Another seminal study by Esmaillzadeh et al assessed the relationship between whole-grain intake and metabolic syndrome from an epidemiological perspective. This study showed that diets rich in wholegrain are inversely correlated with the risk of metabolic syndrome (14) and it was one of the few studies that had addressed such a diet-disease relationship in a large population at the time. Many later studies in TLGS addressed nutritional findings and are thoroughly reviewed in a review article in this issue.

\subsection{Blood Pressure and Hypertension (15)}

As TLGS was designed to assess the status of cardiovascular risk factors and to subsequently inform national policies on approaching these risk factors (4), it was well equipped to produce information on hypertension as a major modifiable cardiovascular risk factor. Epidemiological data on the status of hypertension in Iran was available when the TLGS was started, however, the sample size and sampling method of the TLGS gave it a unique position in this regard. Initial findings in the TLGS showed that mean systolic and diastolic blood pressure were higher in men than in women $(119.5 \pm 17.1$ vs. $116.1 \pm 16.8 \mathrm{mmHg}, \mathrm{P}<$ 0.001 for systolic and $77.4 \pm 10.8$ vs. $76.9 \pm 10.0 \mathrm{mmHg}, \mathrm{P}<$ 0.05 for diastolic blood pressure). A crude prevalence rate of $22.9 \%$, with an age-adjusted prevalence of $20.4 \%$ (CI 95\%: 19.2 - 21.6) for men and $25.1 \%$ (CI 95\%: $24.0-26.2 \%$ ) in women $(\mathrm{P}<0.001)$, was reported (4). These prevalence data was not totally similar to previous reports, which could be due to differences in sample size, environmental and cultural factors.

More analyses of the initial TLGS data demonstrated an increase in the prevalence of hypertension with age in both sexes. Hypertension in 20 - 29 year-old men was about twice that of women of the same age group. While no difference was detected between men and women in the 30 - 39 year-old group, in adults 40 years and over hyperten- 


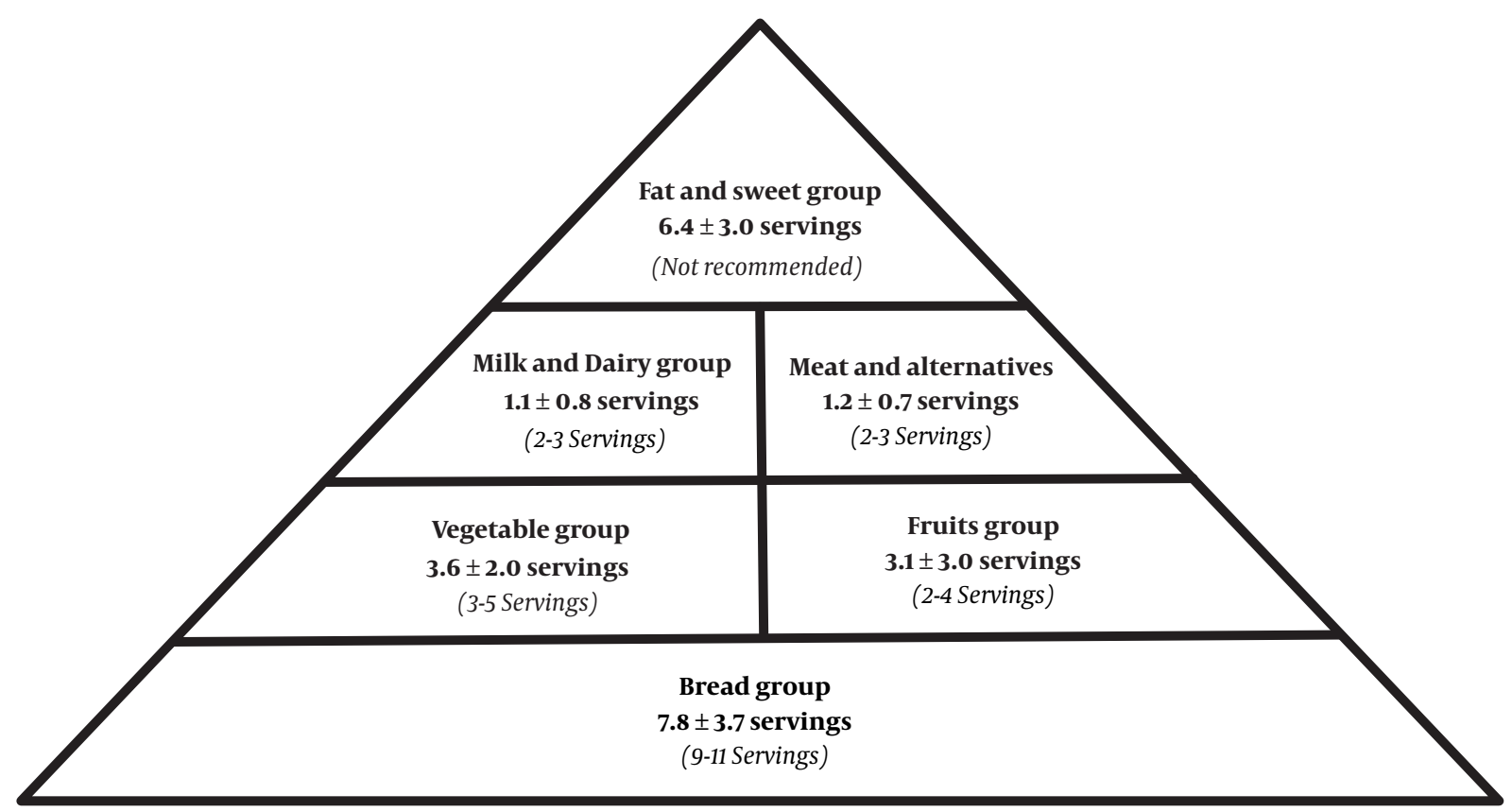

Figure 2. Mean servings of intake of various food groups in the TLGS population in comparison with the Food Guide Pyramid. Values in Bold are from TLGS, and Food Guide Pyramid values are presented in Italics.

sion was more prevalent in women than in men. The reported age and sex-specific differences in hypertension in TLGS were generally consistent with other studies despite subtle differences. Studies on hypertension in TLGS has been ongoing and a review of all the findings is presented in a separate article in this issue.

In its initial years, the TLGS was used as a powerful tool to address more profound questions that were subjects of extensive controversies. In one instance, TLGS researchers questioned the relative significance of systolic and diastolic blood pressure (SBP and DBP) measurements in classification of hypertension according to the international standard of Sixth Report of the Joint National Committee on Detection, Evaluation, and Treatment of High Blood Pressure (JNC-IV) (16). This study concluded that the role of SBP in classification of hypertension according to JNC-VI was more significant only in older adults, and that DBP had a more prominent role in other age groups.

TLGS helped the investigator ask more directed questions regarding NCDs. For instance, another aspect of blood pressure that was assessed within the context of TLGS was the status of blood pressure in adult population in Tehran with myocardial infarction (MI). Since all TLGS participants undergo an electrocardiography (ECG), a group of participants were selected and their ECG tracings were analyzed according to Minnesota ECG coding criteria and categorized as "probable/possible MI" or "no MI". The mean of two separate blood pressure measurements for each participant was also measured and the prevalence of MI in relation to an index of hypertension was assessed (17). This study revealed that among the population in Tehran, MI was more prevalent in hypertensive patients and that after adjustment for age, sex, and body mass index, patients with ECG-defined MI had significantly lower diastolic blood pressure. This study also provided some information about pulse pressure and how it related to blood pressure in the presence or absence of MI. Many similar studies have since tried to elaborate on the causes and associated risk factors of NCDs within the context of TLGS.

\subsection{Dyslipoproteinemia}

A less thoroughly investigated area in Iran at the time when TLGS was initiated was the prevalence of dyslipoproteinemia and distribution of lipoprotein values in urban regions. This coincided with assimilation of more Western lifestyle habits in terms of diet and physical activity by the Iranian population. An epidemiological survey conducted within the framework of TLGS (18) aimed to address this issue and revealed that Tehranian adults had higher levels of total cholesterol, LDL cholesterol (LDL-C) and triglycerides, 
and slightly lower HDL cholesterol (HDL-C) compared with data reported by similar studies in other industrialized countries.

In another early report (19), TLGS investigators performed a more thorough assessment of HDL-C as a common lipid disorder in coronary artery diseases in the TLGS population and highlighted age, sex, hypertriglyceridemia, obesity, truncal obesity, cigarette smoking and passive smoking as determinants of HDL-C. Further studies in later years continued to elaborate on the status of dyslipidemia in the context of TLGS and an overview of the findings of these studies are presented in an article in this issue.

3.6. Diabetes Mellitus, Impaired Glucose Tolerance and Metabolic Syndrome

Among the most important initial findings of TLGS was the prevalence of known diabetes mellitus, new cases of diabetes mellitus (DM), and impaired glucose tolerance (IGT) among different age groups in an adult population in Tehran (Figure 3). These findings highlighted the fact that in both sexes, there was an increase in the prevalence of both DM and IGT (4).

At around the time of TLGS initiation, a number of studies in Iran had reported the prevalence of individual cardiovascular risk factors. However, an analysis of these risk factors as a cluster was not available. TLGS presented an opportunity for examining the prevalence of such a cluster that is known as metabolic syndrome. In one of the early publications out of TLGS, Azizi et al. performed a thorough analysis of various components of metabolic syndrome based on ATP III (adults treatment panel III) criteria and found the age-standardized prevalence of metabolic syndrome in Tehran to be 33.7\% (CI 95\%: 32.8 - 34.6), which was higher than what many studies had reported at the time (20). They also showed that this syndrome was more common among women, with the most common metabolic abnormality being low HDL cholesterol. The pattern, trend and other aspects of this syndrome were further analyzed in more details in future studies. Moreover, TLGS reported cumulative incidence of cardiovascular (CV) risk factors in different age groups in adults (Figure 4).

\subsection{Findings on Children and Adolescents}

When TLGS was launched, a few scattered studies had evaluated lipid profiles in the Iranian population in general, and more specifically in the pediatric and adolescent population in Iran $(21,22)$. This type of information was not readily available even in the Middle East as a region.
Less than three years from its conception, TLGS provided a detailed report on the status of serum lipid levels in a representative population of Iranian children and adolescents in an encompassing article (23), highlighting specifications of dyslipoproteinemia in the Iranian children and adolescents in comparison to global reports. Most importantly, this report showed that this population suffered higher TC, TG, and LDL-C levels and lower HDL-C levels; and that the age distribution of dyslipoproteinemia was different. As such, it set the stage for further national epidemiological research in this field, while providing evidence for designing more precise and efficient health policies and public health campaigns in an era of lifestyle shift in Iran.

This was not the only early TLGS study that looked at a burdensome health issue in adolescents. In an initial report out of TLGS, hypertension among children and adolescents was reported to be slightly more prevalent in boys than in girls, although the difference did not reach statistical significance in that analysis ( $12.7 \%$ vs $10.9 \%$, NS) (4). One comprehensive study set out to determine predictors of cardiovascular disease (CVD) risk factors in the adolescent population of TLGS through the use of anthropometric measurements, dietary recall interviews, blood pressure measurements and lipid profiles. The results revealed strong positive correlations between BMI and blood pressure (both systolic and diastolic) in boys and girls. Some other dietary and lifestyle factors were also identified as predictors of CVD risk factors (24). Moreover, TLGS delineated the cumulative frequency of CVD risk factors in different age groups of Tehranian children and adolescents (Figure 5) (4). Future studies in TLGS also focused on children and adolescents and to date, this population has been an important component in TLGS.

\section{Discussion}

Initial findings from TLGS highlighted that the prevalence of CV risk factors were considerably high among the adults in a population that, at the time, was representative of the Iranian population. The reported figures were higher than those in industrialized countries such as Canada and the United States (25-28). This included a lower prevalence of antiatherogenic factors such as HDL-C compared with industrialized countries (25). Low HDL-C could be associated with high saturated fat intake and low physical activity $(29,30)$, both indicators of unhealthy lifestyles. Despite these alarming findings, CVD mortality rates were lower in Iran compared to industrialized countries, probably due to the lower prevalence of hypertension in Iran 


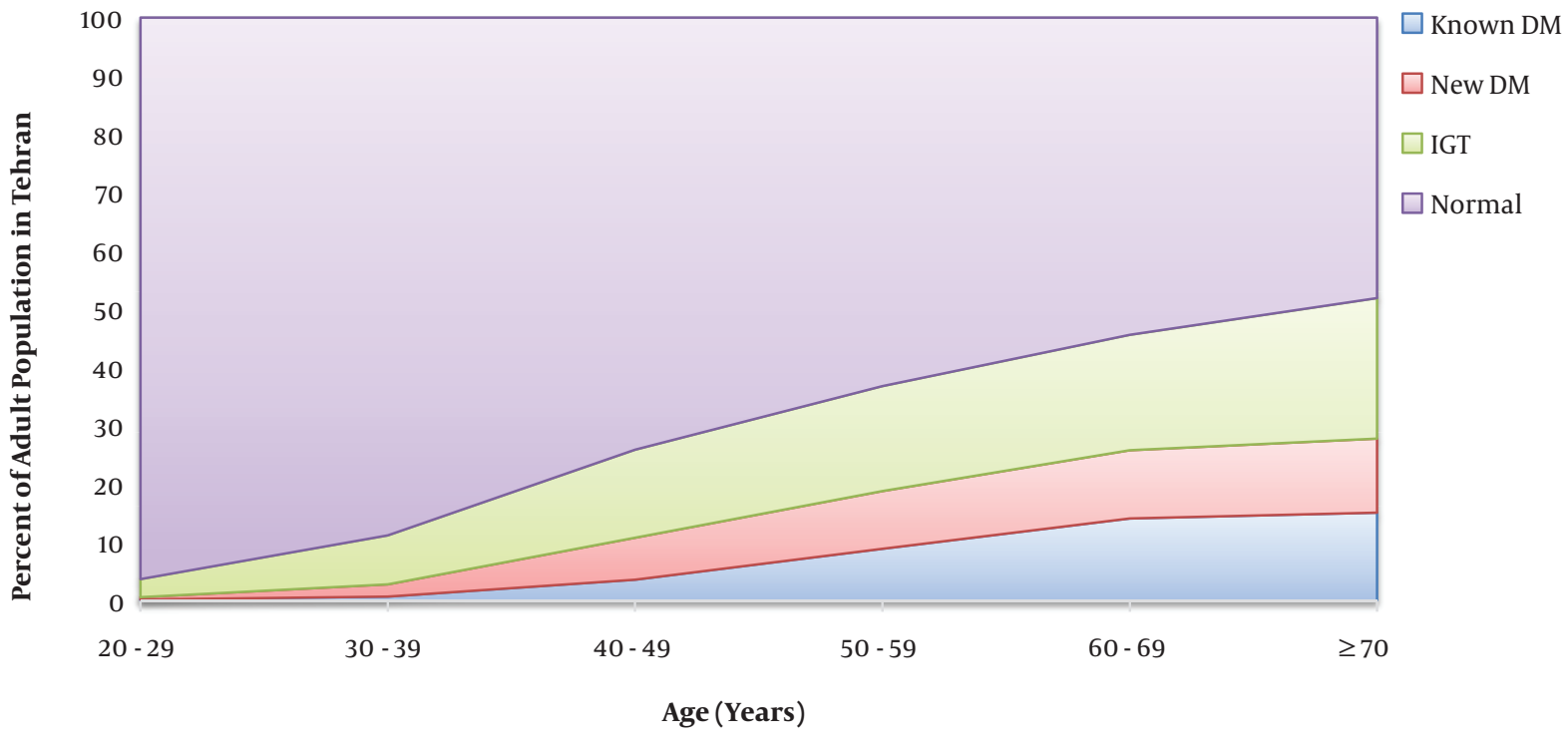

Figure 3. Prevalence of diabetes (DM) and impaired glucose tolerance (IGT) in Tehranian adult population; Tehran Lipid and Glucose Study, Adapted from reference (4).

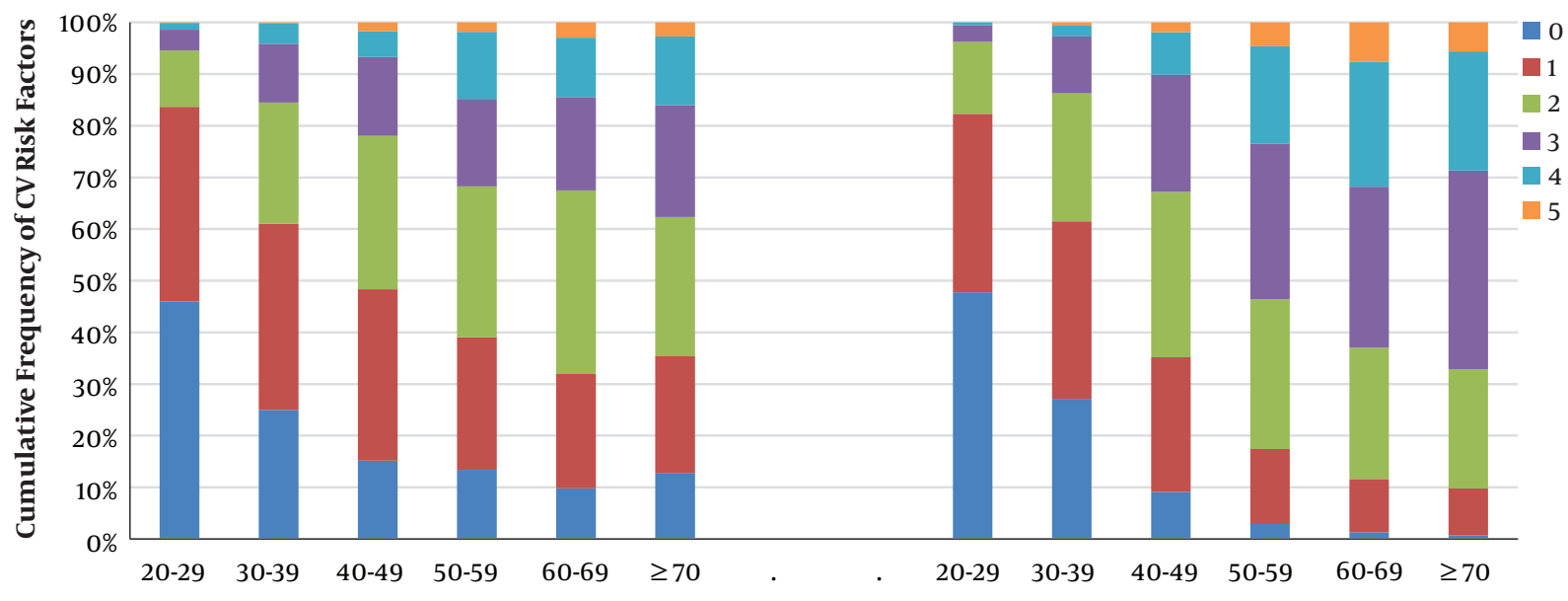

Figure 4. Cumulative frequency of cardiovascular risk factors in adults including hypertension, generalized obesity, central obesity, smoking, diabetes mellitus, total cholesterol $\geq 240 \mathrm{mg} / \mathrm{dL}$, LDL cholesterol $\geq 160 \mathrm{mg} / \mathrm{dL}, \mathrm{HDL}$ cholesterol $<35 \mathrm{mg} / \mathrm{dL}$, and triglycerides $\geq 400 \mathrm{mg} / \mathrm{dL}$ in Tehranian adult population, Tehran Lipid and Glucose Study, Adapted from reference (4).

(26-28). More worrying was the fact that children and adolescents followed a similar pattern and the percentage of Iranian children and adolescents with one or more CV risk factors was higher than the reports out of the United States (31-33). This indicated that a higher mortality among the adult population and a future adult life with significant metabolic and CV morbidity for the children and adolescents were expected in Iran.

The figures reported in the initial phases of the TLGS also differed with those out of other countries in the re- gion. For instance, mean LDL-C concentrations, a major atherogenic lipoprotein, in women in Tehran was higher than those reported in Saudi Arabia (34). Such differences in observations suggested that variations in metabolic health parameters existed in the same geographical region and that many factors were at play and needed to be identified.

In conclusion, this paper highlights the findings of the initial stages of TLGS and points to the alarming trends in the cardiovascular risk factor and nutritional changes 


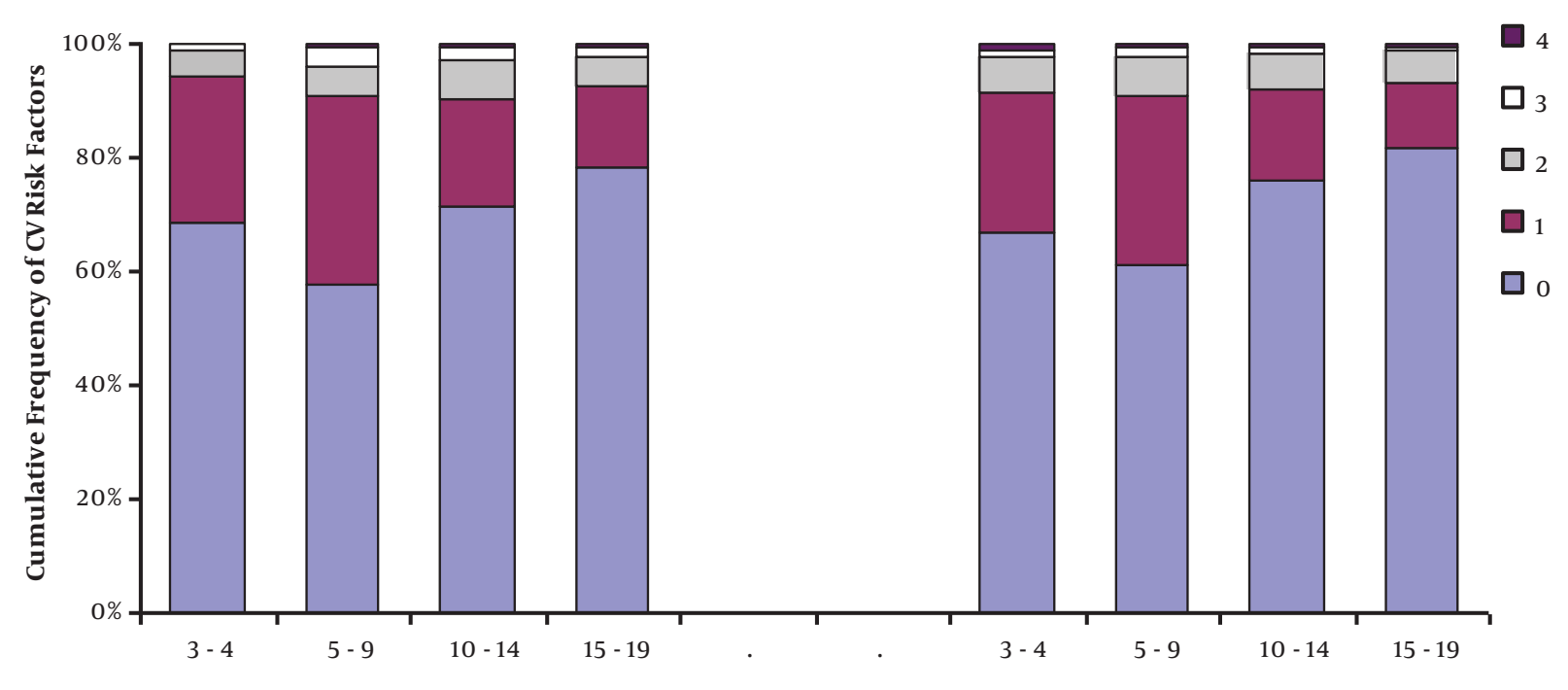

Figure 5. Cumulative frequency of cardiovascular risk factors in children and adolescents including hypertension, obesity, total cholesterol $\geq 95$ th, LDL cholesterol $\geq 95$ th, HDL cholesterol $<5$ th, and triglycerides $\geq 95$ th percentile for each age group of children and adolescents, Tehran Lipid and Glucose Study, Adapted from reference $(\overline{4})$

in Iran at that time. The findings revealed the transition in nutrition and lifestyle that Iran was, and still is, going through. By showing that more than half of adults at the time were at increased risk of cardiovascular and metabolic diseases, and that children and adolescents in Iran were en route to a more morbid adulthood, TLGS became of significant assistance in designing and implementation of prevention programs, public health policies, health education programs, and an integrated public health approach. This landmark initial study became the stepping stone for an interventional phase of TLGS which resulted in crucial and valuable findings in the future.

\section{References}

1. Azizi F, Mehran L. Experiences in the prevention, control and elimination of iodine deficiency disorders: A regional perspective. East Mediterr Health J. 2004;10(6):761-70. [PubMed: 16335762].

2. Ordookhani A, Mirmiran P, Hajipour R, Hedayati M, Azizi F. Screening for congenital hypothyroidism in the Islamic Republic of Iran: Strategies, obstacles and future perspectives. East Mediterr Health J. 2002;8(4-5):480-9. [PubMed: 15603028].

3. Azizi F, Ghanbarian A, Momenan AA, Hadaegh F, Mirmiran P, Hedayati $\mathrm{M}$, et al. Prevention of non-communicable disease in a population in nutrition transition: Tehran Lipid and Glucose Study phase II. Trials. 2009;10:5. doi: 10.1186/1745-6215-10-5. [PubMed: 19166627]. [PubMed Central: PMC2656492].

4. Azizi F, Rahmani M, Emami H, Mirmiran P, Hajipour R, Madjid M, et al. Cardiovascular risk factors in an Iranian urban population: Tehran Lipid and Glucose Study (phase 1). Soz Praventivmed. 2002;47(6):40826. [PubMed: 12643001].

5. Sarraf-Zadegan N, Boshtam M, Malekafzali H, Bashardoost N, SayedTabatabaei FA, Rafiei M, et al. Secular trends in cardiovascular mortality in Iran, with special reference to Isfahan. Acta Cardiol. 1999;54(6):327-33. [PubMed: 10672288].

6. Mendis S, Abegunde D, Yusuf S, Ebrahim S, Shaper G, Ghannem H, et al. WHO study on prevention of recurrences of myocardial infarction and stroke (WHO-PREMISE). Bull World Health Organ. 2005;83(11):8209. [PubMed: 16302038]. [PubMed Central: PMC2626468].

7. Hadaegh F, Harati H, Ghanbarian A, Azizi F. Prevalence of coronary heart disease among Tehran adults: Tehran Lipid and Glucose Study. East Mediterr Health J. 2009;15(1):157-66. [PubMed: 19469439].

8. Unwin N, Alberti KG. Chronic non-communicable diseases. Ann Trop Med Parasitol. 2006;100(5-6):455-64. doi: 10.1179/136485906X97453. [PubMed: 16899148].

9. Darnton-Hill I, Nishida C, James WP. A life course approach to diet, nutrition and the prevention of chronic diseases. Public Health Nutr. 2004;7(1A):101-21. [PubMed: 14972056].

10. Nissinen A, Berrios X, Puska P. Community-based noncommunicable disease interventions: Lessons from developed countries for developing ones. Bull World Health Organ. 2001;79(10):963-70. [PubMed: 11693979]. [PubMed Central: PMC2566669].

11. Mirmiran P, Esmaillzadeh A, Azizi F. Detection of cardiovascular risk factors by anthropometric measures in Tehranian adults: Receiver operating characteristic (ROC) curve analysis. Eur J Clin Nutr. 2004;58(8):1110-8. doi: 10.1038/sj.ejcn.1601936. [PubMed: 15280905].

12. Mirmiran P, Mohammadi F, Baygi F, Kalantary N, Azizi F. [Assessment of dietary intake based on the food guide pyramid in a group of Tehranian adults]. Razi J Med Sci. 2003;9(32):767-78. Persian.

13. Mirmiran P, Mohammadi F, Allahverdian S, Azizi F. Estimation of energy requirements for adults: Tehran Lipid and Glucose Study. Int J Vitam Nutr Res. 2003;73(3):193-200. doi: 10.1024/0300-9831.73.3.193. [PubMed: 12847996].

14. Esmaillzadeh A, Mirmiran P, Azizi F. Whole-grain consumption and the metabolic syndrome: A favorable association in Tehranian adults. Eur J Clin Nutr. 2005;59(3):353-62. doi: 10.1038/sj.ejcn.1602080. [PubMed: 15536473].

15. Azizi F, Ghanbarian A, Madjid M, Rahmani M. Distribution of blood pressure and prevalence of hypertension in Tehran adult population: Tehran Lipid and Glucose Study (TLGS), 1999-2000. J Hum Hypertens. 2002;16(5):305-12. doi: 10.1038/sj.jhh.1001399. [PubMed: 12082490]. 
16. Azizi F, Rashidi A, Ghanbarian A, Madjid M. Is systolic blood pressure sufficient for classification of blood pressure and determination of hypertension based on JNC-VI in an Iranian adult population? Tehran Lipid and Glucose Study (TLGS). J Hum Hypertens. 2003;17(4):287-91. doi:10.1038/sj.jhh.1001539. [PubMed:12692573].

17. Ghanbarian A, Rashidi A, Madjid M, Azizi F. Blood pressure measures and electrocardiogram-defined myocardial infarction in an Iranian population: Tehran Lipid and Glucose Study. J Clin Hypertens (Greenwich). 2004;6(2):71-5. [PubMed: 14872144].

18. Azizi F, Rahmani M, Ghanbarian A, Emami H, Salehi P, Mirmiran P, et al. Serum lipid levels in an Iranian adults population: Tehran Lipid and Glucose Study. Eur J Epidemiol. 2003;18(4):311-9. [PubMed: 12803371].

19. Azizi F, Raiszadeh F, Salehi P, Rahmani M, Emami H, Ghanbarian A, et al. Determinants of serum HDL-C level in a Tehran urban population: The Tehran Lipid and Glucose Study. Nutr Metab Cardiovasc Dis. 2002;12(2):80-9. [PubMed: 12189907].

20. Azizi F, Salehi P, Etemadi A, Zahedi-Asl S. Prevalence of metabolic syndrome in an urban population: Tehran Lipid and Glucose Study. Diabetes Res Clin Pract. 2003;61(1):29-37. [PubMed: 12849921].

21. Rafiei M, Boshtam M, Sarraf-Zadegan N. Lipid profiles in the Isfahan population: An Isfahan cardiovascular disease risk factor survey, 1994. East Mediterr Health J. 1999;5(4):766-77. [PubMed: 11338699].

22. Sarraf-Zadegan N, Boshtam M, Mostafavi S, Rafiei M. Prevalence of hypertension and associated risk factors in Isfahan, Islamic Republic of Iran. East Mediterr Health J.1999;5(5):992-1001. [PubMed: 10983540].

23. Azizi F, Rahmani M, Madjid M, Allahverdian S, Ghanbili J, Ghanbarian A, et al. Serum lipid levels in an Iranian population of children and adolescents: Tehran Lipid and Glucose Study. Eur J Epidemiol. 2001;17(3):281-8. [PubMed:11680549].

24. Azizi F, Mirmiran P, Azadbakht L. Predictors of cardiovascular risk factors in Tehranian adolescents: Tehran lipid and glucose study. Int J Vitam Nutr Res. 2004;74(5):307-12. doi: 10.1024/0300-9831.74.5.307. [PubMed: 15628667].

25. MacLean DR, Petrasovits A, Connelly PW, Joffres M, O'Connor B, Little
JA. Plasma lipids and lipoprotein reference values, and the prevalence of dyslipoproteinemia in Canadian adults. Canadian Heart Health Surveys Research Group. Can J Cardiol. 1999;15(4):434-44. [PubMed: 10322253].

26. Centers for Disease C; Prevention. Prevalence of selected cardiovascular disease risk factors among American Indians and Alaska NativesUnited States, 1997. MMWR Morb Mortal Wkly Rep. 2000;49(21):461-5. [PubMed: 10882292].

27. Sempos CT, Bild DE, Manolio TA. Overview of the Jackson heart study: a study of cardiovascular diseases in African American men and women. Am J Med Sci.1999;317(3):142-6. [PubMed: 10100686].

28. Hutchinson RG, Watson RL, Davis CE, Barnes R, Brown S, Romm F, et al. Racial differences in risk factors for atherosclerosis. The ARIC study. Atherosclerosis risk in communities. Angiology.1997;48(4):27990. doi: 10.1177/000331979704800401. [PubMed: 9112876]

29. Hayes KC. Saturated fats and blood lipids: New slant on an old story. Can J Cardiol. 1995;11 Suppl G:39G-46G. [PubMed: 7585292].

30. O'Connor GT, Hennekens CH, Willett WC, Goldhaber SZ, Paffenbarger RS Jr, Breslow JL, et al. Physical exercise and reduced risk of nonfatal myocardial infarction. Am J Epidemiol. 1995;142(11):1147-56. [PubMed: 7485061].

31. Rabbia F, Veglio F, Pinna G, Oliva S, Surgo V, Rolando B, et al. Cardiovascular risk factors in adolescence: Prevalence and familial ag gregation. Prev Med. 1994;23(6):809-15. doi: 10.1006/pmed.1994.1138. [PubMed: 7855114].

32. Andersen LB, Henckel P, Saltin B. Risk factors for cardiovascular disease in 16-19-year-old teenagers. J Intern Med. 1989;225(3):157-63. [PubMed: 2703797].

33. Lauer RM, Connor WE, Leaverton PE, Reiter MA, Clarke WR. Coronary heart disease risk factors in school children: The Muscatine study. J Pediatr. 1975;86(5):697-706. [PubMed: 1133650].

34. al-Nuaim AR, al-Rubeaan K, al-Mazrou Y, al-Attas O, al-Daghari N. Prevalence of hypercholesterolemia in Saudi Arabia, epidemiological study. Int J Cardiol.1996;54(1):41-9. [PubMed: 8792184]. 